\title{
Design e Gestão para o Setor Público: convergências possíveis
}

\section{Design and Management for the Public Sector: dialogical possibilities}

\author{
COSTA, Cezar de; Mestrando; Universidade Federal do Paraná
}

cezardecosta@gmail.com

PAOLIELLO, Piera Consalter; Mestranda; Universidade Federal do Paraná

pieracpaoliello@gmail.com

KISTMANN, Virgínia Souza de Carvalho Borges; Doutora; Universidade Federal do Paraná

vkistmann@ufpr.br

HEEMANN, Adriano; Doutor; Universidade Federal do Paraná

adriano.heemann@gmail.com

\section{Resumo}

Estudos recentes e pesquisas de opinião pública indicam um acentuado declínio na confiança que a população deposita na classe política. Tal situação é intensificada pela identificação da formação de elites, oriundas da sobreposição de interesses, o que ocasiona a disseminação de atitudes de indiferença, conformismo e distanciamento da arena política (AVRITZER; ANASTASIA, 2006). Apesar de existir na literatura qualificada registros da busca de soluções para a crise na representatividade política, a participação dos cidadãos restringe-se ainda a um mecanismo complementar (GUGLIANO, 2004). Após a identificação da ausência de estudos que associem o processo de elaboração de políticas públicas ao campo do Design, desenvolveu-se uma revisão bibliográfica (GIL, 2002). O presente estudo tem como objetivo introduzir uma discussão sobre a possível relação entre a Gestão de Design e políticas públicas, apresentando uma reflexão sobre a complexa e ainda imprecisa tessitura que integra visões de design, gestão, interesses públicos, participação cidadã e funcionamento do sistema político, apresentando algumas considerações entendidas como convergências entre estes diferentes campos.

Palavras Chave: gestão do design; políticas públicas; participação cidadã.

\begin{abstract}
Recent studies and surveys of public opinion indicate a marked decline in the confidence that the population places in the political class. This situation is intensified by the identification of the formation of elites, resulting from the overlapping of interests, which causes the dissemination of attitudes like indifference, conformism and distancing from the political arena (AVRITZER, ANASTASIA, 2006). Although there is in the literature qualified records of the search for solutions to the crisis in political representation, citizen participation is still restricted to a complementary mechanism (GUGLIANO, 2004). After the identification of the absence of studies that associate the process of elaboration of public policies to the field of Design, a bibliographical review was developed (GIL, 2002). This study aims to introduce a discussion about the possible relationship
\end{abstract}


between Design Management and public policies, presenting a reflection on the complex and still imprecise structure that integrates design visions, management, public interests, citizen participation and functioning of the political system, presenting some considerations understood as convergences between these different fields.

Keywords: design management; public policy; citizen participation. 


\section{A crise da democracia representativa e a emergência de modelos participativos de gestão pública: uma contextualização}

É amplamente aceito que o campo do Design tem como objeto de estudo preponderante o aspecto operativo e perceptivo de sistemas de informação e de produção. Contudo, a gestão desse processo criativo perpassa e é influenciado por interesses públicos, sobretudo em tempos de crise política, quando ocorrem mudanças nas noções de mundo e nos modelos políticos. Nesse sentido, as dificuldades que o Brasil enfrenta no campo político, com o questionamento sobre os mecanismos partidários como mediadores entre Estado e sociedade propiciam reflexões importantes sobre a constituição da cultura política no Brasil e, sobretudo, uma reavaliação posto que é constante, não finda - do processo da construção da democracia.

De um modo geral nota-se, tanto pelos estudos recentes quanto pelas pesquisas de opinião pública, um acentuado declínio na confiança que a população deposita nas instituições políticas e, em particular, na classe política. Esse fenômeno parece estar relacionado à sobreposição de interesses, o individual (privado) prevalecendo sobre o coletivo (público), favorecendo a formação de elites (políticas e corporativistas) encasteladas, fenômeno que se desdobra na disseminação de atitudes de indiferença e distanciamento da arena política (SINTOMER, 2010). Além disso, há que se considerar a gradual difusão de uma postura conformista, carregada de uma apatia que pensa não haver nada que se possa fazer para mudar o statu quo, sintomático não só no Brasil, mas em outras democracias pelo mundo (AVRITZER; ANASTASIA, 2006; DIAMOND, 2017).

A democracia representativa, regime político centrado no voto popular que transfere o poder dos representados aos representantes, há muito oferece indícios de um processo de esfacelamento crítico (SINTOMER, 2010). Pelos registros encontrados na literatura do campo da Ciência Política, pelo menos desde a década de 1970 busca-se soluções para o que se denominou de crise da representatividade política (GUGLIANO, 2004). Conforme o autor, a participação direta dos cidadãos na coisa pública restringiu-se a mecanismo complementar, utilizado apenas em situações críticas. Assim, dos instrumentos da democracia direta, apenas a participação eleitoral é regular - desconsiderando-se a influência da obrigatoriedade do voto, vigente no Brasil desde 1932, pelo Código Eleitoral. Plebiscitos, referendos ou mandados de injunção são, assim, considerados excepcionais, e não mecanismos que assegurem uma aproximação às vontades do povo, através da participação cidadã direta (ibid., 2004).

Como desdobramento dessa conjuntura, intensificou-se nos últimos anos um processo de clivagem do debate político: de um lado, discute-se com maior frequência e paixão a participação popular no processo decisório político - corroborando a tese da erosão da representatividade política nos regimes democráticos modernos -, e de outro, emerge com maior intensidade um espírito autoritário, erigido na crença de que uma figura centralizadora do poder e até mesmo a ocupação por forças militares são as únicas alternativas para solucionar esse impasse.

Para compreender a relação existente entre Gestão de Design e políticas públicas e, mais especificamente, o modo como o pensamento subjacente à primeira é capaz de permear o processo de elaboração de políticas públicas, foi necessário um incurso teórico aos referidos temas por meio de uma revisão bibliográfica (GIL, 2002), não tendo sido esta realizada anteriormente no campo do Design. Corroborando Gugliano (2004), os resultados obtidos estão 
alinhados às circunstâncias descritas.

\section{Design, gestão e interesses públicos: em busca de soluções em tempos de crise política}

Seja em um cenário de crise ou não, o Design, enquanto atividade, pode se inserir no domínio político oferecendo uma perspectiva resolutiva. Por meio de conceitos, ferramentas e práticas do Design, é possível munir-se para a resolução de problemas do domínio público (MOZOTA, 2011; MAFFEl; MORTATI; VILLARI, 2012; MULGAN, 2014). As questões e apontamentos apresentados ao longo deste artigo versam sobre as rearticulações entre Estado, como provedor, e sociedade, como requerente, pela perspectiva do Design. Além disso, o trabalho contribui com a disseminação dos temas aqui tratados na agenda de pesquisa sobre gestão pública e design no Brasil, por meio da discussão de alguns fatores que contribuem para o desenrolar do atual cenário sociopolítico - que repercutem também no âmbito do design.

Cabe aqui resgatar a visão de Gui Bonsiepe (2011), estudioso do Design, que se refere à atuação no setor público como uma das seis virtudes atribuídas por ele ao design, uma vez que "[...] os interesses públicos devem ser defendidos vigorosamente em qualquer sociedade que se defina como democrática e que mereça essa classificação" (ibid., p. 37), destacando a necessidade de aproximar o design dos interesses públicos.

Ainda no horizonte do Design, Ezio Manzini (2010) expõe, na apresentação do livro Metaprojeto: o design do design de Dijon De Moraes, visões que considera alinhadas às demandas sociais contemporâneas. O autor sublinha, em meados de 2010, que a próxima economia não se limitaria à lógica de mercado, mas que a configuração econômica emergente envolveria uma variedade de agentes sociais (companhias privadas, instituições públicas, autoridades locais, fundações, iniciativas sociais e associações sem fins lucrativos, organizações da sociedade civil, grupos de cidadãos atuantes etc.), sendo essa nova economia caracterizada especialmente pela inovação social. Ao referido autor, as inovações em vista seriam "[...] criadas e realizadas pelos grupos de pessoas diretamente envolvidas no problema em que têm de solucionar, e não tanto por especialistas ou políticos" (ibidem, p. x). Assim, uma "nova economia" - e, na perspectiva deste artigo, uma nova forma de fazer política e pensar gestão pública - implica novas formas de fazer e pensar design.

Para Dijon De Moraes (2010), autor do livro anteriormente citado, Design é, mais contemporaneamente, a gestão da complexidade e da informação. Para ele, o cenário dinâmico e fluído, e por isso mesmo complexo, deixou de ser, como na "primeira modernidade", tecnicista e linear. É necessário esclarecer a apropriação que Moraes faz do termo complexidade: para o autor, ela está na relação entre pelo menos dois componentes. Onde há um conjunto ou sistema, reside nele algum grau de complexidade, a depender dos componentes e as conexões estabelecidas entre estes. Pizzocaro (2004) afirma que a complexidade está entre a ordem e a desordem, e não nesses extremos. Os sistemas políticos - e indo além, a gestão pública -, bem como seus inúmeros componentes caracterizadores, partindo desta perspectiva, são sistemas complexos: não são de todo ordem ou desordem, mas um entreposto.

Se o Design corresponde, de acordo com a definição de Moraes, à gestão da complexidade 
e da informação, gerir a complexidade, nesse sentido, significa não só combinar intencionalmente os componentes de um determinado sistema/conjunto, mas sobretudo agir sobre as relações que se estabelecem entre eles, perseguindo um "arranjo ideal", que se reconfigura na medida em que nos aproximamos dele. A gestão da informação, nessa mesma direção, implicaria na ordenação dos dados que, a depender das configurações e reconfigurações estabelecidas, possibilitariam a transformação destes em informações, oferecendo suporte para a tomada de decisões e gerando valor para as organizações e para a sociedade (PIZZOCARO, 2004; MORAES, 2010).

Parece haver uma confluência conceitual que possibilita dar contornos ao que alguns estudiosos do Design e da Ciência Política chamam de policy design (MAFFEI; MORTATI; VILLARI, 2012). Ao longo das últimas décadas, emergiram novas linhas de atuação no campo do Design design estratégico, design ficcional, design de serviços, design thinking, entre outras -, marcando uma transição de foco do Design da esfera da produção e do consumo estético (Era Industrial) para o Design como propositor e/ou catalizador de soluções para problemas tanto do âmbito individual quanto do social (BONSIEPE, 2011; MORAES, 2010).

O policy design está entre as vertentes que emergiram nos últimos anos. Do leque de definições para o termo encontradas na literatura, a aproximação mais exitosa às visões delineadas por Moraes e Manzini é apresentada por Maffei, Mortati e Villari (2014), que exploram a ideia de conectar técnicas e abordagens de co-design com o processo de elaboração de políticas públicas. Para os autores, policy design visa projetar colaborativamente "[...] um conjunto de regras, atividades e processos necessários para transformar as condições (sociais) existentes em preferenciais" (ibid, p. 4, trad. nossa). Partindo dessa definição, também não seria equivocado entender policy design como a inserção do design thinking ${ }^{1}$ no âmbito político, visão essa explorada por Lucy Kimbell (2016).

No entanto, embora os discursos que postulam o Design como uma via para a proposição de soluções aos problemas que afligem a sociedade há muito vem somando vozes, a resolução dos problemas de interesse público é atribuída, ainda hoje, quase que estritamente à Gestão Pública, recaindo assim sobre a figura dos políticos (como articuladores) e dos gestores públicos a responsabilidade de resolvê-los. Há uma fenda entre o Design e a Gestão Pública que, a depender do país, estado ou município e dos governos, é maior ou menor. Contudo, é interessante notar também que essa distância tem sido reduzida por meio da Gestão do Design, sobretudo em países que já contam com políticas públicas voltadas ao Design, como Reino Unido, Finlândia e Dinamarca, com visões de governo que objetivam aproximação máxima ao conceito de cidade inteligente $^{2}$ (smart city, do original em inglês) (DAROS; KISTMANN; ZAINA, 2014).

\section{Entre Design e Gestão: convergências para uma atuação no setor público}

\footnotetext{
1 "É a disciplina que utiliza a sensibilidade do designer e métodos para atingir as necessidades das pessoas com o que é tecnologicamente factível e o que a viável estratégia de negócio possa converter em valores para o consumidor e oportunidade de mercado." (MARTIN, 2009, p. 62)

"São sistemas de pessoas utilizando e interatuando com materiais, serviços e financiamento, para catalisar um desenvolvimento econômico, sustentável, resiliente e um alto nível de vida. Estas interações tornam-se smart através de uma utilização estratégica das infraestruturas de informação e comunicação, em um processo de planificação e gestão urbana transparente que reage perante as necessidades sociais e econômicas da sociedade" (DAROS, KISTMANN; ZAINA, 2014, p. 3).
} 
Antes mesmo de tratar da relação entre a Gestão e o Design, e, por conseguinte, sua relação com a Gestão Pública, é necessário esclarecer à qual entendimento de Gestão se aderiu para elaborar sobre ele. Para tanto, convém a definição apresentada por Koontz e Weihrich (2015), por sua objetividade. Para os autores, Gestão é o processo de projetar e manter um ambiente no qual indivíduos, trabalhando em grupos, possam cooperar para a consecução eficiente de objetivos estabelecidos.

Já a relação entre Design e Gestão, ou simplesmente a Gestão de Design, é a implementação do design como um programa formal de atividades dentro de uma corporação, seja por meio da comunicação da relevância das atividades de design para as metas de longo prazo, seja através da coordenação dos recursos de design em todos os níveis da atividade corporativa para atingir os seus objetivos (MOZOTA, 2011; BEST, 2015).

A Gestão do Design pode ocorrer nos três níveis de trabalho: o operacional, o tático e o estratégico (HEEMANN; LIMA; CORRÊA, 2008; MOZOTA, 2011). Para cada nível, há um diferente escopo de gestão. No nível operacional, o Design visa o impacto econômico, focando assim nas demandas do mercado, apresentado por Mozota (2011) como diferenciador. Já no nível tático ${ }^{3}$ o Design é introduzido como coordenador, sendo abordado como uma competência administrativa, com foco na gestão de inovação e de tecnologia, alterando seus métodos de coordenação. Por fim, no nível estratégico o Design assume o posto de competência central, impactando o ambiente da empresa e possibilitando a alteração de sua visão e escopo de negócio, atuando como agente transformador do contexto.

A literatura que versa sobre Gestão de Design é caracterizada sobremaneira pelo foco nos negócios, visando prioritariamente o incremento financeiro e o lucro como resultado da aplicação das atividades e mudanças sugeridas. No âmbito da Gestão Pública, no entanto, os interesses que movem os tomadores de decisão são distintos daqueles do setor privado. Nesse caso, os gestores são incumbidos da organização, formulação, implementação e avaliação das políticas públicas, competência atribuída ao Estado. As políticas públicas, vale esclarecer, representam o modo de operar o Estado e, assim, concretizar uma visão de governo (VIANA, 1996). Thomas R. Dye (1972, p.8), sintetiza a definição de política pública como "[...] o que o governo escolhe fazer ou não fazer". Já Chrispino (2016) deduz, em um exercício de revisão, que política pública é a ação intencional de governo que vise atender às necessidades da coletividade. Para a tomada de decisões e análise das políticas públicas, Laswell afirma que é necessário responder às seguintes questões: quem ganha o quê, por quê e que diferença isso faz.

Frequentemente, e cada vez mais, ouve-se falar sobre as vantagens de optar por uma Gestão Pública de administração privada, alimentando a ideia de que seria muito mais profícuo que a Gestão Pública se desse sob a administração de empresários bem-sucedidos em termos de mercado. Há um evidente esforço em buscar na gestão privada o virtuosismo que se julga faltar à gestão pública. Ocorre que, como bem sublinha Chrispino, "[...] as lógicas da iniciativa privada e da administração pública são muito diferentes" (2016, p. 205). E é precisamente por essas diferenças que se exige, tanto do gestor público quanto do gestor empresarial, diferentes formas de atuar. Para Chrispino, são várias as diferenças que caracterizam os dois campos de ação: valores, lógica

\footnotetext{
3

3 De acordo com Mozota (2011), os níveis da Gestão de Design são o estratégico, o funcional e o operacional. No entanto, Heemann, Lima e Corrêa (2008) identificam esses mesmos níveis descritivamente, com uma alteração no segundo nível (funcional), em que empregam o termo tático, tal como usualmente utilizado na literatura de Gestão que não versa especificamente sobre as atividades de Design. Neste trabalho, o uso dos termos funcional e tático é intercambiável.
} 


\section{de gestão e mesmo a formação, conforme o Quadro 01.}

Quadro 01 - Diferenças entre o gestor empresarial e o gestor público.

\begin{tabular}{|c|c|c|}
\hline & GESTOR EMPRESARIAL & GESTOR PÚBLICO \\
\hline \multicolumn{3}{|c|}{ VALORES } \\
\hline Motivação & Lucro pessoal e material; prestígio pessoal. & Resultados sociais positivos; reconhecimento. \\
\hline Recompensa & Poder econômico. & Resultado social. \\
\hline Projeto pessoal & Destacar-se na média. & Alcançar metas estabelecidas. \\
\hline Energia canalizada & Ao extremo, contra a concorrência. & Para áreas possíveis de ação no âmbito da necessidade social. \\
\hline $\begin{array}{l}\text { Origem dos } \\
\text { recursos }\end{array}$ & Pessoal, ou de grupo de pessoas. & População. \\
\hline \multicolumn{3}{|c|}{ LÓGICA DE GESTÃO } \\
\hline Lógica decisória & Custo versus benefício. & Custo/efetividade. \\
\hline $\begin{array}{l}\text { Procedimento } \\
\text { estratégico }\end{array}$ & Otimizar. & Maximizar. \\
\hline Escolha da equipe & Individual, por seleção/indicação. & Impessoal, por concurso público. \\
\hline $\begin{array}{l}\text { Capacitação da } \\
\text { equipe }\end{array}$ & Programa permanente. & Eventos ocasionais. \\
\hline $\begin{array}{l}\text { Área de fricção e } \\
\text { confronto }\end{array}$ & Externa; concorrência. & Interna; oposição política. \\
\hline Atividade & Regras abertas. & Regras superreguladas. \\
\hline Adversários & Externos. & Internos. \\
\hline $\begin{array}{l}\text { Tempo de } \\
\text { permanência }\end{array}$ & O tempo em que sua gestão é eficaz. & Períodos fixos e curtos de governo. \\
\hline Contexto político & É usuário do contexto político. & É produtor e escravo do contexto político. \\
\hline \multicolumn{3}{|c|}{ FORMAÇÃO DO GESTOR } \\
\hline Eixo & Gira em torno do lucro. & $\begin{array}{l}\text { Ambiente, relações internacionais e institucionais, equilíbrio de } \\
\text { poderes, necessidades coletivas e pessoais, demandas distintas etc. }\end{array}$ \\
\hline $\begin{array}{l}\text { Relação com a } \\
\text { gestão }\end{array}$ & É formado para ser gestor. & É escolhido para ser gestor. \\
\hline $\begin{array}{l}\text { Ferramentas e } \\
\text { questões }\end{array}$ & $\begin{array}{l}\text { Balanços, estoques, mercados, rentabilidade, } \\
\text { créditos, liquidez, produção etc. }\end{array}$ & $\begin{array}{l}\text { Ambiente, relações internacionais e institucionais, equilíbrio de } \\
\text { poderes, necessidades coletivas e pessoais, demandas distintas etc. }\end{array}$ \\
\hline Política & É contexto, vista como restrição. & É o centro e o motivo de existir. \\
\hline Abordagem & Unilateral, dirigida ao lucro. & Multilateral, difusa no coletivo e nas múltiplas demandas. \\
\hline
\end{tabular}

Fonte: Chrispino (2016, p .205). 
Partindo disso, cabe pressupor que as práticas de Gestão de Design, a depender do âmbito em que se inserem, demandam um alinhamento com os valores, a lógica de gestão e também às características da formação do gestor - público ou empresarial. Nesse sentido, interessa ao presente estudo compreender como o pensamento subjacente à Gestão de Design é capaz de permear, de modo vantajoso aos interesses públicos, o processo de elaboração de políticas públicas.

\section{Políticas públicas no nível estratégico de gestão: considerações sobre a participação cidadã no design do ciclo de Políticas Públicas}

As Políticas Públicas (PP's) representam o corpo final de um conjunto de regras, atividades, processos e, evidentemente, enunciados atributivos de valor. A reação e a expectativa das pessoas em relação à política são fatores que influenciam na tomada de decisões políticas e é desse pressuposto que surge o conceito de arena política (policy arena). São exemplos de arenas políticas o Poder Legislativo ou qualquer ministério (arenas formais) e as próprias "ruas", a sociedade em geral (arenas informais). O processo de formulação das PP's geralmente se estrutura na forma de um ciclo (policy cycle), e é nele em que são ordenados de forma racional os conflitos, consensos, coalizões e cisões que surgem nas arenas políticas, estabelecendo uma ponte entre a intencionalidade de ação do governo - ou seja, o entendimento de PP - e a sua efetiva realização no seio da sociedade, que é, afinal, quem financia e é afetada pelo processo decisório (CHRISPINO, 2016).

Na Gestão Pública, as PP's são instrumentos de escopo mais amplo. Delas, derivam programas e iniciativas. Assim, uma única PP pode se desdobrar em diferentes programas, que por sua vez, podem reunir um ilimitado número de iniciativas. O Programa Bolsa Família ${ }^{4}$, por exemplo, é o desdobramento de uma Política Pública de cunho assistencialista, que visa à erradicação da pobreza e da extrema pobreza, atendendo parcialmente à Constituição Brasileira, que determina o fim da pobreza e da marginalização, bem como a redução das desigualdades sociais (BRASIL, 2004). Nesse exemplo, a aprovação de um pacote de medidas de inclusão produtiva para os beneficiários do programa - como a manutenção do benefício para quem conseguir um emprego com carteira de trabalho assinada - pode ser entendida como uma iniciativa.

A Gestão do Design possibilita pensar as estruturas das PP's, instrumento primeiro da Gestão Pública, ao compor um paralelo entre os níveis de gestão - estratégico, tático e operacional - e a arquitetura de funcionamento político das PP's, tal como ilustra a figura 01.

\footnotetext{
4 BRASIL. Lei $N^{\circ}$ 10.836, de 9 de Janeiro de 2004.
} 
Figura 01 - Pirâmide comparativa de níveis de gestão e arquitetura de PP's.

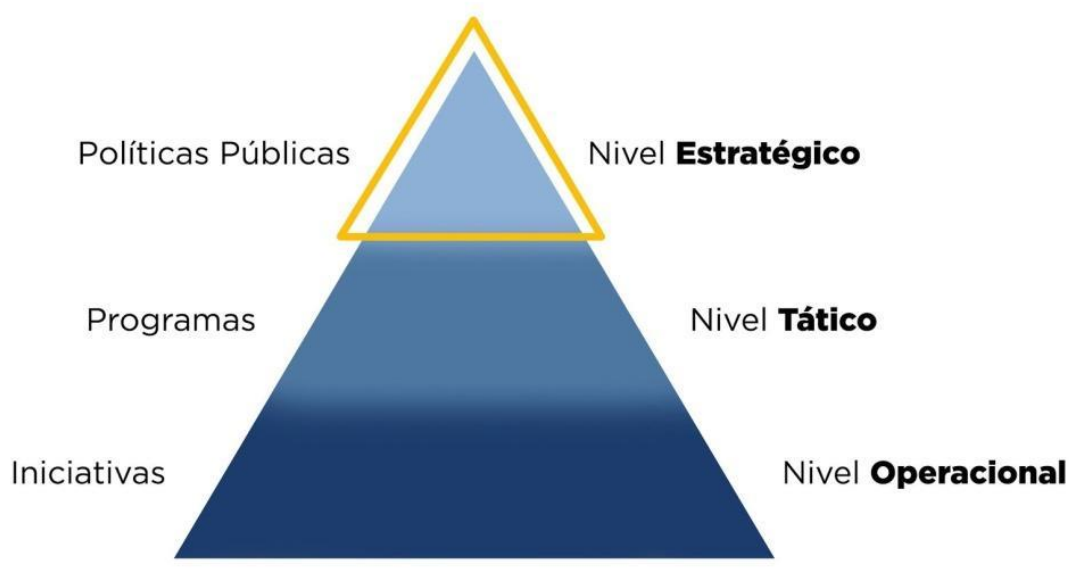

Fonte: os autores (2018).

Se a formulação e implementação das PP's explicitam as prioridades do governo, como vias pelas quais a visão de governo se concretizará, cabe reconhecer que nelas reside um aspecto fortemente estratégico. Ao analisar algumas PP's, é possível notar que estas são relativamente abstratas e geralmente se detém na descrição de um objetivo (ex. erradicar a extrema pobreza), reservando às suas próprias subestruturas componentes (programas e iniciativas) a função de elencar meios para sua realização, o que parece justificar tal característica. Enquanto as PP's são análogas ao nível estratégico, os programas, por conseguinte, se alinham ao nível tático. As iniciativas, por fim, dialogam com a noção de nível operacional, como exposto anteriormente.

Considerando o foco nas PP's, se o que tratamos aqui é, afinal, da dimensão estratégica por trás das políticas públicas, a primeira questão, da perspectiva da Gestão de Design, consiste em entender se há ou não intencionalidade na tomada de decisões para a formulação de uma política pública, seja qual for. Quando há intencionalidade, esta pode provir do posicionamento dos gestores, de processos culturais, de políticos, de pressões internas (outros órgãos, servidores etc.) ou externas (a sociedade, uma situação emergencial etc.).

Pela ótica da Gestão do Design, Mozota (2011) explica que os designers podem contribuir de duas formas nesse processo: pela definição de estratégias deliberadas, em que, diferentemente daquilo que se possa pensar por "deliberativo", as decisões e definições são tomadas de maneira centralizada, por um gestor ou equipe fechada; ou, de uma segunda forma, pelo processo de estratégias emergentes, em que são inseridas "[...] opiniões e ideias de design no processo coletivo de construção de consenso [...] por meio das diferentes coalizões sociais" (ibidem, p.180). A autora pondera que, apesar de os designers não estarem familiarizados com o processo de estratégias emergentes, este é provavelmente o aspecto mais interessante da gestão estratégica do Design, pois explora a "imprecisão" ao longo do processo, infundindo o design progressivamente. 
A conexão estabelecida pela referida autora sublinha a relação entre estratégia e intencionalidade, permitindo situar o processo de PP's junto à compreensão de Design como transformador. Disso implica questionar um aspecto fundamental das PP's: se há transformação, deve existir mudanças. E é precisamente sobre essas mudanças que se debruça a avaliação, quer pela ótica da Gestão Pública, quer pela Gestão de Design. É importante apreciar e qualificar práticas, o que mudou e se essas mudanças proporcionaram melhora na atuação, tanto de um negócio quanto de um governo.

Para Vaz (1994), é importante avaliar regularmente a Gestão Pública a partir da perspectiva da qualidade de vida e do avanço da democracia. Para tal, é fundamental conceber um sistema de avaliação que defina responsabilidades, quem serão os participantes, as etapas, os instrumentos de avaliação, as fontes de informação e os procedimentos para análise. Ademais, o autor considera que, apesar de a avaliação depender das características da gestão que se pretende avaliar, alguns pontos são fundamentais na atuação de governos que priorizem a consolidação da cidadania: participação popular e dos servidores públicos, critérios objetivos de análise, integração entre avaliação global e avaliação setorial da gestão, preocupação com os avanços dos direitos sociais e políticos e transparência na divulgação dos resultados.

$\mathrm{Na}$ avaliação de PP's, espera-se um estudo de relação causal por meio de métodos e técnicas de pesquisa que permitam relacionar os feitos de um programa $x$ aos resultados $y$, baseando-se na coerência mínima entre objetivo, meios e fins desejados (CHRISPINO, 2016). Para Howlett, Ramesh e Perl (2013), há cinco diferentes tipos de avaliação, a partir de uma visão administrativa:

1. Avaliação de processos, no qual o objetivo, em geral, é verificar se um processo pode ser aperfeiçoado de modo que seja mais eficiente;

2. Avaliação do esforço, em que se busca medir o montante de esforços (em pessoal, espaços, comunicação, transporte etc.) que os governos investem para cumprir suas metas, calculados em termos monetários, possibilitando estabelecer um parâmetro inicial que servirá para a determinação da eficiência ou qualidade dos resultados, em um segundo momento.

3. Avaliação de desempenho, onde o foco é a determinação do que está sendo produzido (output) por meio da política. São exemplos as vagas para atendimento em creches, número de jovens com passe estudantil ou inscritos em um determinado curso gratuito. Assim como a avaliação do esforço, a avaliação de desempenho produz dados que são úteis para avaliações posteriores, mais abrangentes e intensivas.

4. Avaliação da eficiência, em que se tenta determinar os custos de uma determinada decisão, julgando se esse mesmo montante e qualidade poderiam ser alcançados de maneira mais eficiente, sendo uma forma de avaliação essencial em tempos de restrições orçamentárias e, geralmente, conduzida por consultores externos.

5. Avaliação da eficácia, também conhecida como auditoria de custo/benefício. Visa descobrir se um programa está cumprindo o que se espera dele. É um dos tipos de avaliação mais úteis aos policy makers, mas também um dos mais complexos. 0 
desempenho de um dado programa é confrontado com os objetivos e, com base nas constatações avaliativas, poderão ser elaboradas recomendações para alterar os programas/políticas. Esse tipo de avaliação demanda muita informação e alto nível de sofisticação para levá-la ao termo.

Esses tipos de avaliação se enquadram em outras categorias, em parte temporais, em parte pela especialidade, que apontam em que momento do ciclo de PP's ocorre a avaliação, ou qual a finalidade desta (avaliação ex-ante, ex-post etc.).

Vale ressaltar que é justamente por meio da avaliação que a sociedade pode acompanhar os avanços e retrocessos na gestão pública, estando a par dos direcionamentos orçamentários. A avaliação, nesse sentido, assume não somente a função de auditoria do planejamento e resultados, mas também de controle. É sabido ser dever do poder público agir tão somente conforme as leis, no entanto é igualmente conhecida a corrupção praticada por parte dos agentes públicos e figuras políticas, alcançando o status de "maior problema" ${ }^{5}$ do Brasil. $O$ parco esforço na criação e aperfeiçoamento de instrumentos de controle político pode ser tanto causa quanto consequência da apatia política dos cidadãos frente ao descompromisso dos agentes públicos e da classe política como um todo. O controle - ou averiguação - pode acontecer ao longo de todo o processo político fazendo com que as instituições e a participação social exerçam um papel basilar nesse processo, intercalando-se ou atuando conjuntamente como controladores internos (Tribunal de Contas da União, Assembléia Legislativa, Ministério Público, Procuradoria Geral da União etc.) e externos (ONG's, sindicatos, conselhos de acompanhamento, associação de moradores, imprensa livre, cidadãos etc.).

No Brasil, a participação cidadã nos espaços de decisão e acompanhamento se iniciou com a consolidação da Constituição da República Federativa do Brasil, de 1988 (CRBF/1988). No país, o principal instrumento de participação tem sido os conselhos (de saúde, assistência social, segurança etc.). Alguns destes conselhos possuem poder deliberativo, outros apenas função consultiva. A função compartilhada desses conselhos é de fiscalização - dos objetivos, meios, resultados e recursos despendidos.

É no contexto de uma democracia participativa, direta ou consociativa, que se abrem canais de participação cidadã. Não se pretende, porém, um aprofundamento na questão da arquitetura política dos diferentes regimes democráticos, uma vez que as pretensões deste artigo estão mais relacionadas com o estabelecimento de um diálogo entre Gestão do Design, instrumentos participativos e o processo de formulação de políticas públicas.

Nesse ínterim, a democracia consociativa, que pode ser entendida como uma derivação conceitual da democracia participativa,é caracterizada pela busca de consensos para o convívio entre os diferentes atores e interesses sociais (TOBA, 2004; CHRISPINO, 2016). São exemplos dessa instituição as conferências nacionais, os planos diretores e os documentos de impacto ambiental. Sob a lógica do consociativismo, "ganha" quem demonstrar melhor articulação e organização (BORGES; LUCE, 2000).

Retomando o discurso de Mozota (2011), ao tratar das distinções entre estratégia

\footnotetext{
${ }^{5}$ c.f. www1.folha.uol.com.br/poder/2015/11/1712475-pela-1-vez-corrupcao-e-vista-como-maior-problema-do-pais.shtml
} 
deliberativa e estratégica emergente a autora sublinha o aspecto da construção de consensos por meio dos quais são inseridas "[...] opiniões e ideias de design no processo coletivo" (p.180), característico do modo emergente de definição estratégica. Uma estratégia emergente, no contexto da gestão empresarial, seria aquela que, pelo uso da imaginação e da lógica, faz emergir da organização - como coletividade organizada em torno de um objetivo - uma resposta a uma oportunidade do ambiente, de modo que resulte em uma vantagem competitiva para a empresa (MINTZBERG, 1987; HENDERSON, 1989). As estratégias emergentes ocorrem diariamente nas empresas e, como pontuam Slater e Narver (1995), são frutos mais da cultura organizacional e do conceito de learning organization ${ }^{6}$ do que dos planejamentos deliberados.

$\mathrm{Na}$ Gestão Pública e, considerando mais especificamente as PP's, as estratégias emergentes - ou, talvez caiba denominar, as PP's de origem participativo-deliberativas poderiam ser entendidas como os consensos que emergem da articulação entre os diferentes atores sociais, em busca de alternativas para solucionar um ou mais problemas que os afetam. Essa concepção incorpora a visão de Manzini (2010), anteriormente explorada, em que o autor, em exercício de vaticínio sobre o Design, considerava que as inovações seriam "[...] criadas e realizadas pelos grupos de pessoas diretamente envolvidas no problema em que têm de solucionar, e não tanto por especialistas ou políticos".

Ao tratar da avaliação da Gestão Pública, Vaz (1994) enfatiza que a discussão com a população sobre as metas e prioridades para o futuro é premente para o processo de avaliação, embora na prática tal abertura seja, por certo, muito mais trabalhosa. Outro ponto salientado pelo autor é o da objetividade da avaliação. Há que se contornar a complexidade implícita no ato de participação e deliberação ${ }^{7}$, bem como decantar informações confiáveis advindas desses processos deliberativos, as quais servirão para fundamentar a tomada de decisão e, consequentemente, legitimar todo o processo, da formulação até a implementação das PP's.

Em seu livro The Fundamentals of Design Management, Kathryn Best (2010) indaga quem detém o poder político, os governos ou os cidadãos. Para a autora, novos modelos políticos baseados em maior transparência são impulsionados pelo "[...] aumento da liberdade de informação, pelas atividades colaborativas dos grupos que exercem pressão sobre as decisões do governo e pelo uso popular das mídias sociais" (p. 17), percepção também alinhada aos apontamentos de Manzini (2010) e Moraes (2010).

A avaliação é igualmente fundamental para a Gestão de Design, uma vez que possibilita investigar os resultados alcançados pelas atividades de gestão (BEST, 2010; MOZOTA, 2011), estabelecendo relações de causa-consequência entre uma atividade de gestão $x$ e resultados $y$. $\mathrm{Na}$ Gestão de Design a avaliação pode tomar por objeto diferentes elementos que, no âmbito da Gestão Pública, há uma mudança de valores que regem a lógica da gestão e que, consequentemente, alteram o objetivo da avaliação. Alguns dos elementos característicos da Gestão de Design podem ser transpostos para o contexto da Gestão Pública.

Enquanto a Gestão de Design com foco no setor privado visa, sobretudo, mensurar o retorno financeiro e de valor agregado (de significado, status), na gestão pública a qualidade pode ser entendida como a relação entre expectativa e realidade daquilo que se materializa por via

\footnotetext{
6 "Organizações habilitadas na criação, aquisição e transferência de conhecimentos e que modifica seus comportamentos a fim de refletir os novos conhecimentos e insights" (GARVIN, 1993, p. 78)

7 Empregado no sentido de "[...] debate com o objetivo de resolver algum impasse ou tomar uma decisão", conforme o Dicionário Houaiss.
} 
política (programas, iniciativas etc.). A "satisfação do cliente" pode ser lida como a satisfação dos cidadãos, ou seja, se a relação entre expectativa e realidade não é frustrada ou a gestão pública entregue mais do que o esperado pelos cidadãos, pode haver aumento da satisfação popular com as decisões de gestão. A "posição da marca no mercado" diz respeito a um comparativo estabelecido entre pares, o que na Gestão Pública está atrelado à esfera de poder de referência. No âmbito da municipalidade, o tráfego de informações sobre a vida pública se acelerou com os avanços tecnológicos observados nas últimas décadas, possibilitando aos munícipes o poder de comparar, mesmo que de maneira pouco criteriosa e aprofundada, os rumos dos diferentes municípios (geograficamente próximos ou não, visto que a internet rompeu as barreiras físicas no processo de disseminação de informações) com o seu próprio, atitude que pode funcionar como um gatilho de percepções, positivas ou negativas, sobre a gestão e vida pública de seu município. Nesse sentido, o município assume o lugar da "marca" e a "posição no mercado" seria o julgamento social que alavanca ou não a imagem do município em relação aos outros, de referência. Já as "metas alcançadas" parecem estar diretamente relacionadas com as PP's: o que se estabeleceu como prioridade foi planejado e entregue à população?

Nesse cenário, o papel do designer (ou policy designer) seria, como a visão explorada por Moraes (2010) pareceu prever, o de um articulador. O entendimento de Design como gestão da complexidade e gestão da informação, comentado pelo estudioso, dialoga com o panorama aqui esboçado: a participação dos cidadãos no processo decisório político implica na inserção de um contingente de indivíduos de difícil mensuração e, junto deles, um sem-fim de demandas e abundância de informações que, ora podem convergir, ora conflitar. Pensar em soluções para os problemas que afligem a coletividade desloca o designer de uma lógica de gestão top-down, uma "amiga de longa data" da gestão empresarial, para um modelo bottom-up, posicionando-o junto à coletividade, e não como uma figura de atuação isolada. Para o modelo bottom-up estruturado pela teoria do desenvolvimento social, a participação em amplas discussões comunitárias, as oportunidades aperfeiçoadas de aprendizagem e o sentimento de empoderamento resultante do conhecimento adquirido nesse processo são precursores necessários para cumprir os objetivos declarados e implícitos do desenvolvimento comunitário (BLANCHARD, 1988; LARISSON, 2002).

Tanto para a elaboração quanto para compor uma matriz de avaliação de PP's, fica evidente a necessidade de considerar em maior medida aspectos relativos à participação e deliberação cidadã, pelos motivos até aqui discutidos, a saber: insatisfação dos cidadãos com a classe política, apatia e distanciamento da vida pública, divergência de interesses entre representantes e representados, questionamento da legitimidade dos representantes na tomada de decisão, corrupção, entre outros. Ao longo do ciclo de uma PP, a avaliação - uma das últimas etapas do ciclo - é tão fundamental quanto o processo deliberativo inicial, que visa discutir o que é prioritário para o futuro da coletividade, quem e como os cidadãos serão afetados pelas decisões.

Percebe-se que o cenário dinâmico e fluido (MORAES, 2010) exige repensar as fronteiras do Design e da Ciência Política para que se possa rompê-las e adequar continuamente suas práticas, respondendo à crescente complexidade e fluxo de informações. O tempo presente demanda, além disso, uma reconceitualização das práticas participativo-deliberativas emergentes, que se estabelecem por meio das redes de agentes sociais, em constante articulação. Manzini (2010) convoca os designers a atuarem como colaboradores, a fim de integrar estas redes de design emergente para alimentá-las pelo compartilhamento do conhecimento de Design - 
especialmente por meio de ferramentas e práticas colaborativas -, instigando a concepção de visões de futuro pela coletividade.

\section{Considerações Finais}

O presente estudo apresenta uma reflexão sobre a complexa e ainda imprecisa tessitura que integra visões de design, gestão, interesses públicos, participação cidadã e funcionamento do sistema político, apresentando algumas considerações entendidas como convergências entre estes diferentes campos. A partir dos apontamentos, é possível argumentar sobre a necessidade de endossar os estudo sobre este tema, de forma a propiciar avanços no plano analítico, bem como subsídios para o processo concreto de transformação de políticas e práticas na gestão pública no país. Considera-se, portanto, passo subsequente ao presente estudo da relação entre teoria da Gestão de Design ao contexto de políticas públicas, a associação de ferramentas e métodos de design colaborativo presentes na literatura qualificada ao contexto em questão.

\section{Agradecimentos}

Os autores agradecem à CAPES e ao CNPq pelo apoio por meio da concessão de bolsas de estudo.

\section{Referências}

AVRITZER, L; ANASTASIA, F. Reforma Política no Brasil. Leonardo Avritzer e Fátima Anastasia (org). Belo Horizonte: Editora UFMG, 2006. 271p.

BEST, K. The Fundamentals of Design Management. Lausanne: AVA Book Production, 2010.

BLANCHARD, D. Empirical strategies of bottom-up development. ICA International IERD Regional Development Symposia. pp. 318-338, 1988.

BONSIEPE, G. Design, Cultura e Sociedade. São Paulo: Blucher, 2011.

BORGES, A. A.; LUCE, F. B. Estratégias Emergentes ou Deliberadas: um estudo de caso com os vencedores do prêmio Top de Marketing da ADVB. RAE - Revista de Administração de Empresas. v. 40, n. 3 Jul./Set. 2000.

BRASIL. Lei No 10.836, de 9 de Janeiro de 2004.

CHRISPINO, A. Introdução ao estudo das políticas públicas: uma visão interdisciplinar e contextualizada. Rio de Janeiro: FGV Editora, 2016.

DAROS, C.; KISTMANN, V.; ZAINA, T. Contribuição do design para as smart cities. Anais do 110 Congresso Brasileiro de Pesquisa e Desenvolvimento em Design, 2014. DOI: 10.5151/designproped-01448. 
DE MORAES, D. Metaprojeto: o design do design. São Paulo: Blucher, 2010.

DIAMOND, L. Para entender a democracia. Tradução: Vitor Adriano Liebel [et al.]. 1. ed. Curitiba: Instituto Atuação, 2017.

DYE, T. Understanding public policy. Nova Jersey: Prentice-Hall, 1972.

GIL, A. C. Como elaborar projetos de pesquisa. 4. ed. ed. São Paulo: Atlas, 2002.

HENDERSON, B. D. The origin of strategy. Harvard Business Review, v. 67, p.139-143, Nov./Dec. 1989.

KOONTZ, H.; HEINZ W. Essentials of Management: An International, Innovation, and Leadership Perspective. 10th ed. New Delhi: McGraw-Hill Education (India) Private Limited, 2015.

LARRISON, C. R. A Comparison of Top-Down and Bottom-Up Community Development Interventions in Rural Mexico: Practical and Theoretical Implications for Community Development Programs. Mexican Studies. Vol. 3, 2002.

MINTZBERG, H. Crafting strategy. Harvard Business Review, v. 65, n. 5, p. 66-75, 1987.

MOZOTA, B. B.; KLÖPSCH, C.; COSTA, F. C. Gestão do design: usando o design para construir valor de marca e inovação corporativa. Porto Alegre: Bookman, 2011.

SINTOMER, Y. O poder ao povo: júris de cidadãos, sorteio e democracia participativa. Belo Horizonte: Editora UFMG, 2010.

SLATER, Stanley F., NARVER, John C. Market orientation and the learning organization. Journal of Marketing, v. 59, n. 3, p. 63-74, Julho, 1995.

VAZ, J. C. Avaliando a gestão. In: Revista Pólis-Ildesfes, n. 24, p. 87-102, Out. 1994. 